\title{
Pharmacological and clinical properties of curcumin
}

\author{
This article was published in the following Dove Press journal: \\ Botanics:Targets and Therapy \\ 23 June 2011 \\ Number of times this article has been viewed
}

\author{
Christopher S Beevers' \\ Shile Huang ${ }^{2}$ \\ 'Department of Pharmacology, \\ Ross University School of Medicine, \\ Picard-Portsmouth, Commonwealth \\ of Dominica; ${ }^{2}$ Department of \\ Biochemistry and Molecular Biology, \\ Louisiana State University Health \\ Sciences Center, Shreveport, LA, USA
}

\begin{abstract}
The polyphenol natural product curcumin has been the subject of numerous studies over the past decades, which have identified and characterized the compound's pharmacokinetic, pharmacodynamic, and clinical pharmacological properties. In in vitro and in vivo model systems, curcumin displays potent pharmacological effects, by targeting many critical cellular factors, through a diverse array of mechanisms of action. Despite this tremendous molecular versatility, however, the clinical application of curcumin remains limited due to poor pharmacokinetic characteristics in human beings. The current trend is to develop and utilize unique delivery systems, chemical derivatives, and chemical analogs to circumvent these pharmacological obstacles, in order to optimize the conditions for curcumin as a chemopreventive and chemotherapeutic agent in diseases such as cancer, diabetes, obesity, Alzheimer's disease, and inflammatory disorders. The present work seeks to review recent studies in the basic pharmacological principles and potential clinical applications of curcumin.
\end{abstract}

Keywords: curcumin, pharmacological properties, signal transduction, cellular targets, cancer, inflammation

\section{Introduction}

Curcumin [1,7-bis(4-hydroxy-3-methoxyphenyl)-1,6-heptadiene-3,5-dione] ${ }^{1}$ (Figure 1) is a major chemical component of turmeric power, produced from the rhizome of the plant Curcuma longa. ${ }^{2}$ Pharmacologically, curcumin has been used as a traditional medicinal agent in Ayurvedic medicine for $\sim 6000$ years. ${ }^{2}$ The pharmacokinetic, pharmacodynamic, and clinical pharmacological properties of curcumin have been extensively studied over the past six decades ( $\sim 3600$ citations in Entrez-PubMed as of the writing of this review). These studies have demonstrated that curcumin functions as an antioxidant, anti-inflammatory, and anti-atherosclerotic; inhibits scarring, cataract, and gallstone formation; promotes wound healing and muscle regeneration; prevents liver injury and kidney toxicity; and exerts medicinal benefits against psoriasis, diabetes, multiple sclerosis, Alzheimer's, HIV disease, septic shock, cardiovascular disease, lung fibrosis, arthritis, and inflammatory bowel disease. ${ }^{2-4}$ Recently, curcumin has garnered interest as a potential anticancer agent, for both chemopreventative and chemotherapeutic purposes. ${ }^{2,5}$ In vitro cell culture and in vivo animal studies have suggested that curcumin may be able to treat numerous types of cancer, including breast cancer, ${ }^{6}$ colon cancer, ${ }^{7}$ kidney cancer, ${ }^{2}$ liver cancer, ${ }^{2}$ leukemia, ${ }^{8-10}$ basal cell carcinoma, ${ }_{11}^{11}$ prostate cancer, ${ }^{12}$ rhabdomyosarcoma, ${ }^{13,14}$ and melanoma. ${ }^{15}$ Curcumin can effectively inhibit almost every major stage of carcinogenesis, including transformation, initiation, promotion, invasion, angiogenesis, and metastasis. ${ }^{2-5}$
Correspondence: Shile Huang

Department of Biochemistry and

Molecular Biology, Louisiana State

University Health Sciences Center,

I50I Kings Highway, Shreveport,

LA 7II30-3932, USA

Tel + I 3186757759

Fax +I 3186755180

Email shuanI@Isuhsc.edu
Botanics:Targets and Therapy 201 I:I 5-18

(C) 20II Beevers and Huang, publisher and licensee Dove Medical Press Ltd. This is an Open Access

Dovepress

http://dx.doi.org/10.21 47/BTAT.SI 7244 
<smiles>COc1cc(/C=C/C(=O)CC(=O)/C=C/c2ccc(O)c(OC)c2)ccc1O</smiles><smiles>COc1cc(/C=C/C(=O)CC(=O)/C=C/c2ccc(O)cc2)ccc1O</smiles>

Demethoxycurcumin

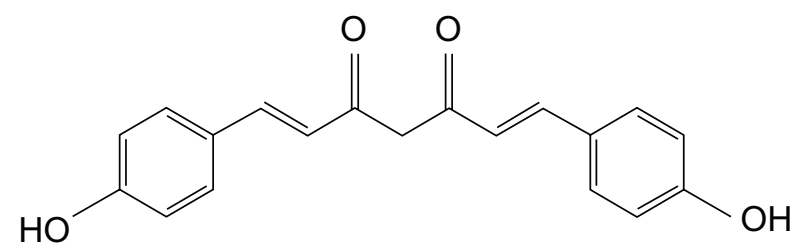

Bisdemethoxycurcumin

Figure I Chemical structure of the curcuminoids.

Curcumin can exert a large range of pharmacological effects such as induction of cell cycle arrest, ${ }^{2}$ inhibition of cellular proliferation/growth, ${ }^{2,14}$ inhibition of cell motility, ${ }^{14}$ induction of apoptosis, ${ }^{2,14}$ and anti-inflammatory action. ${ }^{16,17}$ However, it has been very challenging to uncover the compound's primary cellular targets and mechanisms of action. Any cursory perusal of the literature will indicate that the action mechanisms are complex and that the number of proposed cellular targets is vast. ${ }^{2,5,18}$ To date, it has been described that curcumin targets transcription factors, kinases, enzymes, adhesion molecules, proteases, cell surface receptors, transporters, and apoptotic factors..$^{2-5,18}$ Most attention has been paid to nuclear factor-kappa B (NF-kB; $\sim 400$ references; see the following reviews ${ }^{2,19-25}$ ), c-Jun N-terminal kinase (JNK; 160 references; see ${ }^{2,5}$ ), cyclooxygenase-2 (COX-2; $\sim 130$ references; see ${ }^{2,24,26-29}$ ), protein kinase $\mathrm{C}$ (PKC; $\sim 60$ references; see ${ }^{2,30-32}$ ), Akt ( $\sim 130$ references; $\operatorname{see}^{5,23,33}$ ), glutathione-S-transferase (GST; $\sim 40$ references; see ${ }^{2,34-37}$ ), epidermal growth factor receptor (EGFR; 37 references; see $^{2}$ ), and signal transducer and activators of transcription (STAT; $\sim 25$ references; $\sec ^{22,23}$ ). A new proposed target that has begun to garner interest in recent years is the mammalian target of rapamycin (mTOR; $\sim 17$ references; see ${ }^{18,38,39}$ ).
This review seeks to present evidence from the most recent studies in the field that suggest possible new attractive targets for curcumin; shed a greater light of confirmation on past identified targets of the agent; demonstrate novel ways of exploiting and overcoming the pharmacokinetic challenges presented by the parent compound; further elucidate the therapeutic, preventive, and/or diagnostic utility of curcumin in classically identified pathologies; and suggest the use of curcumin as a novel pharmacological agent for the treatment, prevention, and/or diagnosis of other pathological conditions in human beings.

\section{Chemistry of curcumin}

Curcumin is a hydrophobic natural product that is composed of two phenolic rings, each substituted with a methoxy ether functionality in the ortho-position (Figure 1). The two phenolic rings are joined via an aliphatic unsaturated heptene linker in the para-position that also contains an $\alpha, \beta$ diketonic functionality on carbon- 3 and -5 . Various studies have indicated that the diketone functionality can undergo reversible tautomerization between enolic- and ketonic-forms ${ }^{40}$ Tautomerization of curcumin occurs in a $\mathrm{pH}$-dependent manner, with the bis-keto form predominating in acidic and neutral solutions, and the enol-form in alkaline solutions. ${ }^{3}$ While in the bis-keto form, carbon- 4 of the heptene linker can function as an extremely powerful proton donor, while the enol form functions mainly as an electron donor, chemical activity that bestows upon curcumin its antioxidant properties. ${ }^{3}$ In fact, the antioxidant properties of curcumin are several times more potent than those exhibited by vitamin E. ${ }^{41}$ Curcumin also functions as a pro-oxidant under certain conditions, ${ }^{2}$ most likely as a result of electron transfer to molecular oxygen to generate reactive oxygen species (ROS).$^{42}$ Commercially produced curcumin is composed of three major components, commonly referred to as the curcuminoids: curcumin I (described above), demethoxycurcumin (curcumin II; lacks one methoxy functionality), and bisdemethoxycurcumin (curcumin III; lacks both methoxy functionalities) (Figure 1)., ${ }^{2,3}$

\section{Recent studies on curcumin pharmacokinetics}

The pharmacokinetics of curcumin have been extensively studied in animals, and to a lesser extent in humans, and are reviewed thoroughly in Sharma et al. ${ }^{43}$ In summary, the vast majority of these studies have demonstrated that curcumin exhibits extremely poor gastrointestinal absorption/oral bioavailability, and undergoes metabolism to form several 
chemical species, including curcumin glucuronide, curcumin sulfate, hexahydrocurcumin, tetrahydrocurcumin, and dihydrocurcumin. One of the major experimental initiatives in the field in recent years has been the development of curcumin derivatives, curcumin analogs, and curcumin-drug vehicle combinations that display enhanced absorption and systemic bioavailability as compared to the parent drug.

A group from Thailand recently synthesized succinyl derivatives of all three of the main curcuminoids. ${ }^{44}$ The hydrolysis of curcumin diethyl disuccinate in phosphate buffer ( $\mathrm{pH}$ 7.4) and in human plasma followed pseudo firstorder kinetics. The $\mathrm{k}_{\text {obs }}$ and $\mathrm{t}_{1 / 2}$ of this compound in phosphate buffer was significantly greater than that of curcumin, indicating greater chemical stability. ${ }^{44}$ The compound also demonstrated the ability to successfully release curcumin in human plasma. ${ }^{44} \mathrm{~A}$ Chinese study utilized reversed phasehigh performance liquid chromatography to demonstrate that intravenous injection of a curcumin prodrug (curcumin didecanoate) provided sustained plasma levels of curcumin itself. ${ }^{45}$ A group in India investigated the effect of complexing curcumin with phosphatidylcholine (CU-PC) on curcumin pharmacokinetic parameters. ${ }^{46}$ Ex vivo studies using the everted intestine sac technique demonstrated that CU-PC displayed significantly greater absorption than curcumin alone. ${ }^{46}$ In vivo studies in rats and in vitro studies utilizing isolated rat hepatocytes revealed that CU-PC displayed enhanced bioavailability and pharmacokinetics, and significantly increased hepatoprotective activity compared to curcumin alone. ${ }^{46}$ Similarly, a group from the University of Athens, Greece, recently synthesized a stable curcumin formulation composed of egg-phosphatidylcholine (EPC) liposomes (drug to lipid molar ratio of $1: 14$ ) that demonstrated an $\sim 14 \%$ release of the compound in fetal bovine serum after 96 hours of incubation. ${ }^{47}$

A recent randomized, double-blind, crossover clinical study investigated the effect of a phospholipid lecithin formulation of standardized curcuminoids (Meriva ${ }^{\circledR}$ ) on relative absorption of the compounds. ${ }^{48}$ Meriva administration increased curcuminoid absorption 29-fold compared to an unformulated curcuminoid mixture, with demethoxycurcumin achieving the greatest absorption and systemic bioavailability. ${ }^{48}$ Only phase- 2 metabolites of the curcuminoids could be detected. However, the curcuminoid concentration in plasma remained significantly lower than that required for inhibition of most of curcumin's identified anti-inflammatory targets. ${ }^{48}$

A Chinese laboratory synthesized a curcumin-loaded spherical core-shell structure nanoparticle composed of methoxy polyethylene glycol-poly (caprolactone) block copolymers (mPEG-PCL). ${ }^{49}$ Investigations revealed that curcumin was incorporated into $\mathrm{mPEG}-\mathrm{PCL}$ nanoparticles with high encapsulation efficiency, could be released in a sustained manner, was efficiently transported into cells via endocytosis, and intracellularly localized primarily around nuclei. ${ }^{49}$ An Indian group formulated curcumin nanoparticles (nanocurcumin) that possess a narrow particle size distribution in the range of 2 to $40 \mathrm{~nm}$, and was freely dispersible in water in the absence of surfactants. ${ }^{50}$ Wayne State University in the USA prepared a curcumin microparticle complex using poly(D,L-lactide-co-glycolide) polymer that displayed a 76\% drug encapsulation efficiency. ${ }^{51}$ Curcumin release from these microparticles was sustained over a 4-week period in vitro, and a single subcutaneous injection in mice sustained curcumin concentration in the liver for $\sim 1$ month.${ }^{51}$ A group from Louisiana State University in the USA synthesized a nanoparticle complex consisting of curcumin and rubusoside. ${ }^{52}$ The aqueous solubility of curcumin dramatically increased in the presence of rubusoside, remained stable in physiological conditions, did not precipitate out of solution upon dilution, and demonstrated efficacy against human colon, breast, and pancreatic cancer cells in vitro. ${ }^{52}$ A group from Chulaglongkorn University in Thailand recently synthesized a curcumin loaded monopolymeric nanosphere (ethylcellulose; C-EC) and a curcumin loaded dipolymeric nanosphere (methylcellulose and ethylcellulose; C-ECMC) that both adhered to stomach mucosal epithelial cells (as revealed by scanning electron microscopy). ${ }^{53}$ A curcumin implant utilizing poly (epsilon-caprolactone) as a polymeric matrix, released curcumin in a biphasic release pattern with Higuchi kinetics (1.8 times greater release in vivo than in vitro). ${ }^{54}$ Approximately $60 \pm 20 \mathrm{ng} / \mathrm{g}$ curcumin was found in the liver of test animals 4 days after implantation and remained constant at $8-15 \mathrm{ng} / \mathrm{g}$ for up to 35 days. $^{54}$

A recent study conducted in China demonstrated that application of Gelucire 44/14 with curcumin increased the apparent permeability coefficient of curcumin 1.86-fold across excised rabbit cornea, and promoted curcumin ocular bioavailability as evidenced by a 1.77-fold maximal increase in the area under the curve for the compound. ${ }^{55}$ A Taiwanese group also recently synthesized a eucalyptol microemulsion vehicle (eucalyptol, polysorbate 80, ethanol, water) for transdermal delivery of curcumin that increased the percutaneous permeation rate of the compound 15.7-fold compared to the use of formulations with eucalyptol only. ${ }^{56}$

A recent study elucidated a unique mechanism of curcumin metabolismby purifying an enzyme from Escherichia coli isolated from human feces. ${ }^{57}$ CurA (also known as NADPH-dependent 
curcumin/dihydrocurcumin reductase) metabolized curcumin in a two-step reduction process that produced dihydrocurcumin as an intermediate and tetrahydrocurcumin as the end product. $^{57}$

\section{Recent studies on curcumin: pharmacodynamics and clinical pharmacology mechanisms of action, pharmacological effects, and potential clinical applications}

\section{Antimicrobial and antiviral effects}

Several recent studies have highlighted the potential usefulness of curcumin as an antimicrobial and antiviral agent. Nanocurcumin (described above) displayed much greater aqueous dispersion than curcumin against Staphylococcus aureus, Bacillus subtilis, E.coli, Pseudomonas aeruginosa, Penicillium notatum, and Aspergillus niger. ${ }^{50}$ Nanocurcumin displayed very effective antibacterial activity and transmission electron microscopy analysis revealed that nanocurcumin particles effectively broke bacterial cell walls, inducing a bactericidal effect. ${ }^{50}$ Curcumin demonstrated antimicrobial action against Helicobacter pylori infection in mice via downregulation of matrix metalloproteinase-3 (MMP-3) and MMP-9 expression. ${ }^{58}$ Curcumin demonstrated antifungal activities against 14 strains of Candida in vitro. ${ }^{59}$ In the cases of $C$. albicans and C. glabrata, curcumin significantly inhibited fungal cell $\mathrm{H}^{+}$extrusion in the absence/presence of glucose, decreased ergosterol content of the fungal cell membrane, and decreased proteinase secretion from the fungal cells, though these effects were not as potent as those exhibited by the antifungal azole fluconazole. ${ }^{59}$

Curcumin suppressed HIV-1 replication pathways by blocking transactivator of transcription (Tat)-induced long terminal region (LTR) transactivation. ${ }^{60}$ Specifically, curcumin reversed Tat-mediated downregulation of histone deacetylase 1 (HDAC1) expression, Tat-mediated dissociation of HDAC1 from LTR, and p65/NF- $\mathrm{kB}$ binding to LTR promoters. ${ }^{60}$ Curcumin also blocked Tat-induced phosphorylation of p65 and IкB kinase, as well as Tat-mediated downregulation of AMP-activated protein kinase and acetyl-CoA carboxylase activity. ${ }^{60}$ Biophysical studies revealed that curcumin effectively interacts with the HIV reverse transcriptase enzyme. ${ }^{61}$ Curcumin and two of its derivatives, gallium-curcumin and copper-curcumin, potently inhibited the replication of herpes simplex virus- 1 in vitro. ${ }^{62}$

\section{Inflammation and immunity}

Curcumin has long been touted as a powerful anti-inflammatory and immunomodulatory agent, and recent studies continue to confirm that fact. Curcumin treatment of human intestinal microvascular endothelial cells (HIMEC) in vitro suppressed tumor necrosis factor-alpha (TNF- $\alpha$ )/lipopolysaccharide (LPS)-induced vascular cell adhesion molecule-1 (VCAM-1) expression; inhibited Akt/mitogen-activated protein kinase (MAPK)/NF-кB pathways; and attenuated leukocyte adhesion to TNF- $\alpha /$ LPS-activated HIMEC monolayers under physiological sheer stress conditions. ${ }^{63}$ Curcumin successfully attenuated the transcriptional and translational expression of intracellular cell adhesion molecule-1 (ICAM-1), monocyte chemoattractant protein-1 (MCP-1), and interleukin (IL)-8 in TNF- $\alpha$-stimulated human umbilical vein endothelial cells, resulting in decreased monocyte adhesion (among other effects). ${ }^{64}$ An Indian study demonstrated that dietary curcumin exerted a protective effect in mice against endotoxin shock by inhibiting neutrophil transmigration and infiltration from the vasculature into the liver of LPS-injected animals. ${ }^{65}$ This pharmacological effect was correlated molecularly with significant blockade of ICAM-1 and VCAM-1 expression in liver and lungs. ${ }^{65}$ This improved survival and reduced severity of lethargy, diarrhea, and watery eyes in cases of high-dose endotoxin shock. ${ }^{65}$

An 8-month human study conducted in 100 osteoarthritis patients demonstrated that treatment with Meriva significantly improved clinical (WOMAC score, Karnofsky Performance Scale Index, treadmill walking performance) and biochemical (IL-1 $\beta$, IL-6, soluble CD40 ligand, soluble vascular cell adhesion molecule, erythrocyte sedimentation rate) end points compared to the control group of patients. ${ }^{66}$ An in vivo and in vitro study in mice and cultured renal tubular epithelial cells demonstrated that curcumin was a potent protective agent against LPS-induced renal inflammation. ${ }^{67}$ Specifically, curcumin downregulated LPS-mediated expression of renal MCP-1 at the transcriptional level; inhibited transcription of MCP-1 and IL-2 in cultured cells; partially attenuated the secretion of MCP-1 and IL-8; and inhibited NF- $\kappa$ B DNA-binding. ${ }^{67}$

Curcumin functions as a potent anti-inflammatory agent in periodontal disease. ${ }^{68,69}$ While demonstrating no appreciable effect on alveolar bone resorption or p38 MAPK function, curcumin treatment appeared to effectively inhibit transcriptional and translational expression of pro-inflammatory cytokines and dose-dependently attenuated NF- $\kappa$ B activation in the gingival tissue of rats suffering from experimental periodontal disease. ${ }^{68,69}$ Curcumin significantly reduced 
inflammatory infiltrate, increased the collagen content, and increased fibroblastic cell numbers in gingival tissues. ${ }^{69}$ PEGylated curcumin analogs demonstrated the ability to more powerfully induce the expression and transcription factor activity of the antioxidant defense system regulator nuclear factor (erythroid-derived)-like 2 (Nrf2) more potently than free curcumin in a luciferase-based reporter assay. ${ }^{70}$ Paradoxically, an in vitro study recently demonstrated that curcumin promoted prostanoid production in the presence of exogenous arachidonic acid by stimulating the expression of COX-2, prostaglandin $\mathrm{I}_{2}$ synthase ( $\mathrm{PGI}_{2} \mathrm{~S}$ ), and membraneassociated prostaglandin E synthase-1 (mPGES-1) at the transcriptional level in human coronary artery endothelial cells. $^{71}$

An in vivo study in rats revealed that orally administered curcumin, in combination with the compounds myrcene and cineol, exerted immunomodulatory effects in cases of exposure to the persistent environmental pollutant 2,3,7,8tetrachlorodibenzo-p-dioxin (TCDD). ${ }^{72}$ Specifically, the curcumin-myrcene-cineol combination reduced TCDDstimulated $\mathrm{CD}^{+}$lymphocyte counts, while significantly increasing $\mathrm{CD}^{+}, \mathrm{CD}^{+}, \mathrm{CD} 161^{+}, \mathrm{CD} 45 \mathrm{RA}$, and $\mathrm{CD} 4{ }^{+} \mathrm{CD} 25^{+}$ lymphocyte counts. ${ }^{72}$ This combination of agents also upregulated the antioxidant defense system in rats exposed to TCDD, protecting the liver from oxidative stress. ${ }^{73}$ In vitro studies using mouse $\mathrm{CD} 4^{+} \mathrm{T}-\mathrm{lym}$ hocytes demonstrated that curcumin exerts some of its immunomodulatory effects by suppressing IL-2, forkhead box P3 (Foxp3), and CD25 expression; inhibiting I-2 receptor (IL-2R)-mediated phosphorylation of signal transducer and activator of transcription $5 \mathrm{~A}$ and janus kinase 3; and downregulating the suppressor function of $\mathrm{CD}^{+} \mathrm{CD} 25^{+}$regulatory T-cells. ${ }^{74}$ Another study revealed that the polyphenolic compound was able to inhibit store-operated $\mathrm{Ca}^{2+}$ entry through inhibition of calcium release activated calcium current $\left(\mathrm{I}_{\mathrm{CRAC}}\right)$ in lymphocytes in vitro. ${ }^{75}$ Curcumin also demonstrated the ability to inhibit delayed rectifier potassium current $\left(\mathrm{I}_{\mathrm{Kv}}\right)$ and $\mathrm{I}_{\mathrm{SK} 4}{ }^{75}$

\section{The cardiovascular system}

In recent years, there has been a growing interest in the potential pharmacological effects (particularly protective effects) of curcumin in the cardiovascular system. ${ }^{76} \mathrm{~A}$ study conducted in Romania demonstrated that curcumin was able to reverse the pro-inflammatory action of the cytokine resistin in human endothelial cells. ${ }^{77}$ Curcumin, and an extract prepared from Morus alba leaves, inhibited P-selectin and fractalkine expression; reduced nicotinamide adenine dinucleotide phosphate (NADPH) activation and monocyte adhesion to human endothelial cells; and prevented an increase in intracellular ROS levels. ${ }^{77}$ In light of the fact that all of these events are regulated by resistin, these results suggest that curcumin may represent a novel therapeutic agent in resistin-mediated vascular pathologies. ${ }^{77}$ Curcumin-mediated inhibition of CREB-binding protein (CBP)/p300 disrupted hypoxia-inducible factor- $1 \alpha$ mediated expression of pro-angiogenic genes in human lung microvascular endothelial cells, including plateletderived growth factor, vascular endothelial growth factor (VEGF), placental growth factor, and plasminogen activator inhibitor- $1 .{ }^{78}$ Dietarily administered curcumin and tetrahydrocurcumin were both able to prevent $\mathrm{L}-\mathrm{N}^{\mathrm{G}}$-nitroarginine methyl ester-induced vascular dysfunction and hypertension in rats. ${ }^{79}$ Specifically, curcumin and tetrahydrocurcumin were able to suppress blood pressure elevation, decrease vascular resistance, and restore vascular responsiveness, and these pharmacological effects appeared to be mediated through suppression of endothelial nitric oxide synthase expression in aortic tissue and plasma nitrate/nitrite ratios. ${ }^{79}$ Both compounds also functioned as antioxidants, by reducing vascular superoxide production, decreasing oxidative stress, and increasing glutathione levels. ${ }^{79}$ Curcumin exerts protective antioxidant effects on blood platelets in vitro by inhibiting peroxynitrite-mediated carbonylation of blood plasma and platelet proteins, partially preventing 3-nitrotyrosine formation in plasma proteins, and inhibiting thiobarbituric acid reactive substance generation in platelets and blood plasma. ${ }^{80}$

A study out of the University of Illinois in the USA demonstrated that curcumin dose-dependently prevented copper sulfate-mediated oxidation of low-density lipoproteins (LDL) in vitro, an event that is associated with thrombosis and atherosclerosis. ${ }^{81}$ A study conducted in Taiwan revealed that curcumin efficiently inhibited TNF- $\alpha$-mediated migration of human aortic smooth muscle cells in vitro (an event also associated with atherosclerosis), and that these results were correlated with a downregulation of MMP-9 expression/ activity, ROS production, and NF- $\kappa \mathrm{B}$ nuclear translocation. ${ }^{82}$ Four-month administration of $20 \mathrm{mg} / \mathrm{kg}$ - day curcumin to apolipoprotein $\mathrm{E}$ knockout mice $\left(\mathrm{apoE}^{-/}\right)$resulted in a $50 \%$ reduction in the number of atherosclerotic lesions and a 5-fold increase in caveloin-1 expression. ${ }^{83}$ In oxidizedLDL-treated rat vascular smooth muscle cells in vitro, curcumin significantly diminished cellular lipid droplet number and area; downregulated levels of total cholesterol, cholesterol ester, and free cholesterol; elevated expression of caveolin-1; and inhibited sterol response element binding 
protein 1 nuclear translocation. ${ }^{83} \mathrm{~A}$ similar study revealed that dietarily administered $0.3 \mathrm{mg} /$ day/mouse curcumin for 4 months significantly inhibited atherogenesis in $\operatorname{apoE}^{-/}$ LDLR $^{-/-}$(low density lipoprotein receptor) mice. ${ }^{84}$ Eightweek administration of curcumin to rats fed a high-fat diet caused a significant decrease in serum triglyceride, total cholesterol, and LDL-cholesterol levels, and the atherogenic index of the animals. ${ }^{85}$ These results were correlated with an increase in the transcriptional expression of cholesterol $7 \alpha$-hydroxylase, the rate limiting enzyme in bile acid synthesis. ${ }^{85} \mathrm{~A}$ recent in vitro study indicated that curcumin may prevent cholesterol gut absorption by downregulating the expression and transcription factor activity of SREPB-2, resulting in significant downregulation of transcriptional and translational expression of the cholesterol transporter Niemann-Pick C1-like 1 in human intestinal colorectal adenocarcinoma cells. ${ }^{86}$

\section{Cancer}

Of all the possible clinical applications of curcumin, none has garnered more interest and investment of research resources and manpower than the potential use of curcumin as a cancer chemopreventative and chemotherapeutic agent. This interest and this voluminous amount of investigations continue unabated. One anticancer aspect of curcumin that has attracted heightened attention in the past several years is the anti-angiogenic potential of the compound..$^{87,88}$ Treatment with curcumin alone or in combination with the chemotherapeutic agent carboplatin caused a significant reduction in microvessel density, the plasma concentration of VEGF, and the percentage of fetal liver kinase-1 (Flk-1)rich tumors in an in vivo Ehrlich ascites carcinoma murine model, suggesting that curcumin displays anti-angiogenic potential. ${ }^{89}$ Curcumin significantly inhibited the growth, survival, migration/invasion, and angiogenic potential of adenoid cystic carcinoma cells in vitro and in vivo, and these effects of curcumin were correlated with downregulation of VEGF and MMP-2/9, and the inhibition of the mTOR and NF- $\mathrm{KB}$ pathways. ${ }^{90}$ In vivo, curcumin significantly reduced the emergence of Opisthorchis viverrini- and $N$-nitrosodimethylamine-induced cholangiocarcinoma in hamsters through a variety of mechanisms, including the inhibition of angiogenesis as evidenced by decreased translational expression of VEGF and microvessel density. ${ }^{91}$ Subcutaneous injection of curcumin microparticles synthesized from poly(D,L-lactideco-glycolide) inhibited VEGF expression and disrupted tumor microvessel development in nude mice bearing human breast adenocarcinoma cell xenografts. ${ }^{92}$
A Korean study demonstrated that curcumin inhibited IL-2-mediated induction of inducible NOS expression and nitric oxide production, and stimulated the proliferation, survival, and cytotoxic action of lymphocytes and macrophages during IL-2 stimulation in a mouse acites tumor model. ${ }^{93}$ Curcumin effectively disrupts the physical and functional interactions between integrin $\alpha 6 \beta 4$ and EGFR, leading to inhibition of integrin $\alpha 6 \beta 4$ and EGFR-dependent functions in carcinoma cells. ${ }^{94}$ Curcumin was also able to block EGF-mediated mobilization of integrin $\alpha 6 \beta 4$ to the leading edges of migrating cells (both lammelipodia and filopodia) suggesting a possible mechanism for the compound's antimotility and anti-invasion action against breast carcinoma cells. ${ }^{94} \mathrm{~A}$ proteomic study revealed that curcumin-mediated induction of human breast cancer cell apoptosis in vitro correlated with major changes in translational expression of 12 proteins, including downregulation of transactivation response DNA-binding protein-43, splicing factor 2 /alternative splicing factor, and eukaryotic initiation factor 3i, and upregulation of 3-phosphoglycerate dehydrogenase, endoplasmic reticulum protein 29 , and platelet-activating factor acetylhydrolase IB subunit $\beta .{ }^{95}$ In addition, C-EC and C-ECMC nanospheres demonstrated free radical scavenging ability and exerted cytotoxic effects against human breast cancer cells and human hepatoblastoma cells in vitro..$^{53}$

Curcumin demonstrates synergy with the chemotherapeutic agent paclitaxel against cervical cancer in vivo and in vitro. ${ }^{96}$ Combination therapy with curcumin and paclitaxel in mice synergistically reduced tumor incidence and tumor volume, and this was correlated with curcumin-mediated downregulation of the NF- $\kappa B$, Akt, and MAPK pathways. ${ }^{96}$ Pre-exposure of cervical cancer cells to curcumin in vitro potently potentiated paclitaxel-mediated apoptosis. ${ }^{96}$ Curcumin inhibited cell growth, proliferation, and survival of human cholangiocarcinoma cells in vitro by abolishing activation of NF- $\mathrm{\kappa B}$; suppressing activation of STAT3; inducing expression of peroxisome proliferator-activated receptor gamma (PPAR- $\gamma$ ) and the death receptors DR4 and DR5; inhibiting the Akt pathway; and downregulating the expression of numerous pro-cell survival and pro-cell proliferation proteins. ${ }^{97}$ EPC liposomal curcumin (described earlier) demonstrated greater cytotoxic effect against multidrug resistance-phenotypic human colon cancer cell lines than free curcumin $\mathrm{did},{ }^{47}$ while curcumin succinate prodrugs (described earlier) displayed $\mathrm{IC}_{50}$ values of 1.8-9.6 $\mu \mathrm{M}$ against colon cancer cells in vitro. ${ }^{44}$ Curcumin induced autophagic-mediated death in human colon cancer 
cells by functioning as a pro-oxidant, as treatment with $\mathrm{N}$-acetylcysteine (NAC), an antioxidant and ROS scavenger, prevented this occurrence. ${ }^{98}$ Another study supported these findings by demonstrating that curcumin-mediated suppression of E2F4 expression in human colon cancer cells was mediated by ROS production, as treatment with NAC reversed this phenomenon. ${ }^{99}$

In a recent open-label, nonrandomized, Phase IIa clinical trial, 41 patients meeting specific criteria were given oral curcumin ( $2 \mathrm{~g}$ or $4 \mathrm{~g}$ day) for 30 days. ${ }^{100}$ Patients receiving either dose showed no significant decrease in the levels of the pro-carcinogenic COX-1/2-produced eicosanoids $\mathrm{PGE}_{2}$ and 5-hydroxyeicosatetraenoic acid in either aberrant crypt foci (ACF) or normal mucosa. ${ }^{100}$ The group receiving $4 \mathrm{~g}$ /day did show a $40 \%$ reduction in the number of $\mathrm{ACF}$, and this was correlated with a five-fold increase in posttreatment curcumin/conjugate plasma concentration. ${ }^{100} \mathrm{~A}$ human study conducted in China revealed that curcumin administration to colorectal cancer patients increased patient body weight, decreased TNF- $\alpha$ serum concentration, increased tumor cell apoptosis, and enhanced expression of p53 in tumor tissue. ${ }^{101}$ mPEG-PCL-based curcumin-loaded nanoparticles (described earlier) showed dose-dependent cytotoxicity in vitro against rat glioma cells. ${ }^{49}$ Intravenous administration of mPEG-PCL curcumin micelles more potently inhibited tumor cell-induced angiogenesis and colon carcinoma cell growth in vivo than did free curcumin. ${ }^{102}$ Curcumin significantly inhibited the proliferation of human leiomyosarcoma cells through inhibition of the mTOR pathway, as rapamycin exerted the same effect, though curcumin, but not rapamycin, stimulated apoptosis of these same cells in a concentration-dependent manner. ${ }^{103}$ Curcumin induced caspase-3 and -8-dependent apoptosis in human liposarcoma cells in vitro and in vivo by inducing endoplasmic reticulum stress via inhibition of the function of sarcoplasmic/endoplasmic reticulum $\mathrm{Ca}^{2+}$ ATPase 2 in a dose-dependent manner. ${ }^{104}$

Administration of a nanoparticle-encapsulated curcumin formulation induced $\mathrm{G}_{2} / \mathrm{M}$ cell cycle arrest and apoptosis, and decreased anchorage-independent clonogenic growth of human medulloblastoma and glioblastoma cell lines in vitro. ${ }^{105}$ These pharmacological effects were correlated with downregulation of the insulin-like growth factor pathway, attenuation of STAT3 levels, and inhibition of Hedgehog signaling. ${ }^{105} \mathrm{~A}$ recent study revealed that curcumin is able to attenuate ionizing radiation-induced NF- $\mathrm{KB}$ activity, and telomerase and human telomerase reverse transcriptase transcriptional expression in human neuroblastoma cells. ${ }^{106}$ Curcumin demonstrated synergy with arabinoxylan rice bran to inhibit the proliferation, induce $\mathrm{G}_{0}-\mathrm{G}_{1}$ arrest, and modulated the expression of Bcl-2 family members to favor apoptosis induction in human multiple myeloma cells in vitro. ${ }^{107}$ Curcumin reversed resistance to the topoisomerase I inhibitor irinotecan in nonsmall lung cancer cells, through disruption of the NF- $\kappa$ B pathway. ${ }^{108}$ Curcumin significantly reduced the viability of human oral cancer cells in vitro via downregulation of Notch-1 and NF- $\mathrm{BB},{ }^{109}$ and inhibited the proliferation and invasiveness of human tongue squamous cell carcinoma cells, by dramatically altering their genetic profile, influencing the activity of $280+$ genes. ${ }^{110} \mathrm{~A}$ study in Spain revealed that curcumin inhibited the in vitro viability of human oral squamous cell carcinoma cells, and that it worked synergistically with irradiation to more potently inhibit that viability. ${ }^{111}$

A chemopreventative study revealed that curcumin dramatically disrupted wingless $(\mathrm{Wnt}) / \beta$-catenin signaling pathway-mediated transcriptional activity in human androgen-dependent prostate cancer cells, but not in human androgen-independent prostate cancer cells. ${ }^{112}$ This disruption was the result of curcumin-mediated downregulation of transcription factor-4, CBP, and p300 protein levels, and resulted in $\mathrm{G}_{2}$ cell cycle arrest. ${ }^{112}$ Curcumin treatment of human pancreatic cancer cell tumor xenografts significantly reduced in tumor volume and angiogenic potential. ${ }^{113}$ Curcumin successfully inhibited cellular proliferation by inducing G2-M arrest and inducing apoptosis, and these effects correlated with increased phosphorylation of Chk2, increased expression of cyclin B1 and cell division cycle-2. ${ }^{113}$ Interestingly, curcumin stimulated the transcriptional expression of COX-2 and VEGF, but no corresponding increase in protein levels was seen. ${ }^{113}$ It was observed that curcumin stimulated the expression of the RNA binding proteins CUGBP2/CELF2 and TIA-1, and increased the association of CUGBP2 with COX-2 and VEGF mRNA, leading to a significant increase in their half-lives. ${ }^{113}$

\section{The central nervous system}

Much attention has been placed on the neuroprotective and neurotherapeutic potential of curcumin in recent years. ${ }^{114}$ A Chinese study investigated the potential of curcumin as a therapeutic agent in Alzheimer's disease in vitro. ${ }^{115}$ In human neuroblastoma cells, curcumin dose- and time-dependently decreased the transcriptional and translational expression of glycogen synthase kinase- 3 beta, increased the transcriptional and translational expression of $\beta$-catenin and cyclin $\mathrm{D} 1$, and stimulated $\beta$-catenin nuclear translocation, suggesting that curcumin activates the $\mathrm{Wnt} / \beta$-catenin signaling 
pathway. ${ }^{115} \mathrm{~A}$ recent Japanese study strongly suggests that curcumin may bind directly to amyloid- $\beta$ (A $\beta$ ) oligomers and fibrils, especially to globulomer and $A \beta$-derived diffusible ligand (ADDL). ${ }^{116} \mathrm{~A}$ chemical entity composed of $\mathrm{a}\left[\mathrm{M}(\mathrm{CO})_{3}\right]^{+}\left(\mathrm{M}=\mathrm{Re},{ }^{99 \mathrm{~m}} \mathrm{Tc}\right)$ core with curcumin bound to it as a bidentate $\mathrm{OO}$ ligand was recently synthesized. ${ }^{117} \mathrm{This}$ complex demonstrated strong binding to $\beta$-amyloid plaques, indicating that this chemical entity could be utilized as a radioimaging probe, particularly in cases of Alzheimer's disease. ${ }^{117}$

A Chinese study investigated the potential antidepressive action of curcumin utilizing the exogenous corticosterone (CORT) administration-induced model of depression in rats. ${ }^{118}$ Curcumin therapy significantly reversed depressionlike behavior induced by CORT (as evidenced by rat sucrose consumption and performance of the forced swim test), and this appeared to be mechanistically linked to curcuminmediated restoration of brain-derived neurotrophic factor (BDNF). ${ }^{118}$ The anti-epileptic potential of curcumin was revealed in mice, as oral administration of the polyphenol dose-dependently suppressed pentylenetetrazole-induced kindling, and reduced malondialdehyde and glutathione levels in murine brain tissues. ${ }^{119}$ Curcumin dose-dependently protected PC12 cells in vitro from A53T alpha-synuclein induced apoptosis by reducing intracellular ROS, mitochondrial depolarization, cytochrome c release, and caspase-3/9 activation. ${ }^{120}$ An in vitro study using primary cultures of astrocytes and cortical neurons from rats demonstrated that curcumin provided neuroprotection and anti-inflammatory action in the case of N-methyl-D-aspartic acid (NMDA) toxicity by enhancing expression of the regulated upon activation, normal T-cell expressed, and secreted (RANTES) via activation of the phosphatidylinositol-3 kinase (PI3K) and MAPK signaling pathways. ${ }^{121}$

Curcumin administration increased the resolution of hematomas in a murine model of intracerebral hemorrhage (ICH). ${ }^{122}$ This pharmacological effect was associated with curcumin-mediated downregulation of pro-inflammatory mediators (TNF- $\alpha$, IL-6, IL-1 $\beta$ ), reduction of blood-brain barrier disruption, and attenuation of vasogenic edema. ${ }^{122}$ These pharmacological actions also resulted in a significant improvement in neurological outcome scores in ICH mice. ${ }^{122}$ Orally administered curcumin exerted a strong protective effect in rats who suffered from spinal cord injury via its antioxidant potential. ${ }^{123}$ Specifically, curcumin treatment significantly increased the concentration of superoxide dismutase and decreased the concentration of malondialdehyde in the serum. ${ }^{123}$ Curcumin also exerted a protective and therapeutic effect in the CNS following sciatic nerve crush (SNC). ${ }^{124}$ In rats experiencing SNC, curcumin treatment reduced the loss of A- and B-cell volume and number, reduced the loss of satellite cell number, and significantly improved motor function. ${ }^{124}$

\section{Diabetes}

Because of the increasing evidence that the pathogenesis of type 2 diabetes mellitus (T2DM) and obesity is connected to inflammation, curcumin has emerged as a potential drug of interest for diabetic and obesity pharmacology. ${ }^{125,126}$ A recent Egyptian study investigated the potential of curcumin as a therapeutic agent for the treatment of diabetes in vivo. ${ }^{127}$ Mice suffering with experimental diabetes were administered $10 \mathrm{mM}$ curcumin intraperitoneally for 28 days in combination with or without a single bone marrow transplantation. ${ }^{127}$ Curcumin treatment significantly reversed streptozotocin-induced hyperglycemia, glucose intolerance, hypoinsulinemia, and pancreatic islet damage; attenuated pancreatic lipid peroxidation; upregulated antioxidant enzyme activity; and suppressed serum levels of TNF- $\alpha$ and IL-1 $\beta .{ }^{127}$ A 16 -week in vivo study revealed that curcumin treatment significantly reduced the induction of diabetic retinopathy in rats. ${ }^{128}$ Specifically, curcumin showed significant hypoglycemic activity; positively modulated activity of antioxidant enzymes and molecules; reduced retinal levels of pro-inflammatory cytokines, TNF- $\alpha$, and VEGF; and prevented endothelial cell organelle degeneration and the thickening of capillary basement membranes in the retina. ${ }^{128}$

Another Egyptian study investigated the possibility of curcumin use in the therapy of T2DM. ${ }^{129}$ Fifteen days of oral administration of curcumin to rats fed with a high fat diet for 60 to 75 days demonstrated an anti-hyperglycemic effect/ improved insulin sensitivity and an anti-lipolytic effect, by attenuating TNF- $\alpha$ levels and plasma free fatty acid levels, respectively. ${ }^{129}$ Curcumin treatment of hepatic stellate cells (HSC) prevented high level glucose-induced cell proliferation, type I collagen production, expression of HSC-activating genes, and HSC intracellular glucose levels. ${ }^{130}$ Curcumin also abrogated glucose transporter 2 (GLUT2) membrane translocation via inhibition of p38 MAPK signaling, and reduced GLUT2 expression by activation of PPAR- $\gamma$ and de novo glutathione synthesis. ${ }^{130}$ Finally, a Thai study demonstrated the potential for use of curcumin as an antiangiogenic agent in the therapy of diabetes mellitus as treatment of diabetic mice with curcumin ( $60 \mathrm{mg} / \mathrm{kg}$ body weight) over a 4- to 8- week period resulted in a significant reduction in the 
expression of VEGF in renal tissue. ${ }^{131}$ Curcumin functions as a potent irreversible inhibitor of fatty acid synthase (FAS) in 3T3-L1 cells, a mechanism that resulted in a decrease of FAS, PPAR- $\gamma$, and CD36 expression, and in the inhibition of cellular differentiation and lipid accumulation. ${ }^{132}$ A curcumin-polyethylene glycol conjugate (CCM-PEG) sensitized preadipocytes to the cytotoxic effect of curcumin and improved curcumin-mediated inhibition of adipocyte differentiation. ${ }^{133}$

\section{The renal system}

A recent Egyptian study demonstrated that pretreatment with curcumin exerted protective effects in rats subjected to acute renal injury (renal ischemia followed by reperfusion). ${ }^{134}$ Oral administration of curcumin significantly reduced the plasma levels of numerous cytokines following acute renal injury, specifically TNF- $\alpha$, IL-1 $\beta$, IL-12, IL-18, and interferon-gamma (IFN- $\gamma) .{ }^{134}$ Curcumin also reduced apoptosis induction in renal and pulmonary tissue by inhibiting transforming growth factor-beta (TGF- $\beta$ ) and caspase- $3 .{ }^{134}$ A study conducted in the Netherlands investigated the potential use of curcumin as a therapy for autosomal dominant polycystic kidney disease (ADPKD) in vivo. ${ }^{135}$ Curcumin-treated mice carrying a ADPKD-associated gene deletion displayed improved renal histology, and reduced proliferation index, cystic index, and kidney weight/body weight ratios. ${ }^{135}$ Biochemically, these results correlated with curcumin-mediated inhibition of the mTOR and STAT3 pathways. ${ }^{135}$ Curcumin also significantly decreased the production of the pro-inflammatory cytokines IL- 6 and IL-1 $\beta$ by peripheral blood mononuclear cells isolated from human patients suffering from chronic kidney disease. ${ }^{136}$

\section{The respiratory system}

An in vivo study in rats demonstrated that pretreatment with curcumin exerted a potent protective effect on the lungs following cardiopulmonary bypass (CPB). ${ }^{137}$ Specifically, curcumin pretreatment reduced plasma, bronchoalveolar lavage fluid, and lung tissue concentrations of IL-8, TNF- $\alpha$, and MMP-9 caused by CPB. ${ }^{137}$ Curcumin also downregulated lung tissue expression of toll-like receptor 4, myeloid differentiation primary response gene 88 , and $\mathrm{NF}-\kappa \mathrm{B}$, and significantly reduced the lung injury score of the treated rats. ${ }^{137}$ In vitro, curcumin, in combination with maximal doses of genistein, was able to potentiate the channel activity of cystic fibrosis transmembrane conductance regulator (CFTR) bearing the G551D mutation up to $50 \%$ of the function of the wild type CFTR. ${ }^{138} \mathrm{Co}$-application of curcumin and genistein over a lower concentration range was also able to rescue the gating defect of G551D-CFTR synergistically. ${ }^{138}$

\section{Other body systems}

A recent study demonstrated a possible mechanism for the usefulness of curcumin as an agent for the treatment of gastrointestinal disorders such as diarrhea, abdominal cramps, and irritable bowel syndrome. ${ }^{139}$ Intragastric administration of a single dose of curcumin to rats significantly decreased the distance traveled by barium sulfate in the small intestine, suggesting that curcumin effectively suppressed intestinal motility. ${ }^{139}$ In the integumentary system, an in vitro study demonstrated that curcumin modulates wound healing biphasically, with low doses $(1-5 \mu \mathrm{M})$ stimulating this homeostatic process, and high doses inhibiting it. ${ }^{140}$ This study suggests that curcumin functions as a hormetin by inducing stress response pathways such as Nrf2 and heme oxygenase-1 (HO-1). ${ }^{140}$ In one of the first studies investigating the effect of curcumin on the reproductive system, it was discovered that curcumin dose-dependently inhibited the forward motility of both murine and human sperm, the capacitation/acrosome reaction, and murine fertilization in vitro. ${ }^{141}$ Intravaginal administration of curcumin in mice also caused a significant reduction in fertility. ${ }^{141}$ Another study demonstrated that intragastrically administered curcumin exerted anti-angiogenic activity in a rat model of endometriosis by significantly reducing heterotopic endometrial microvessel quantity and VEGF translational expression. ${ }^{142}$

\section{Toxicology}

The vast majority of preclinical and clinical studies utilizing curcumin have yet to reveal any significant toxicity associated with the compound. ${ }^{2,3,43}$ In fact, many recent studies suggest that curcumin itself may be a potent anti-toxicological agent against drugs and other toxic compounds. A study conducted in rats demonstrated that pretreatment with curcumin (both single dose and multiple doses) was able to prevent the methemoglobinemia associated with exposure to the antimycobacterial drug dapsone. ${ }^{143}$ Curcumin is able to significantly reduce the incidence of abnormal oro-facial movements in rats treated with the dopamine D2 receptor antagonist haloperidol, and a proteomic analysis revealed that this effect was correlated with an increase in the translational expression of $\mathrm{Bcl}-\mathrm{x}_{\mathrm{L}}{ }^{144} \mathrm{~A}$ recent study demonstrated that curcumin may exert chemopreventative potential in cases of oxidative/nitrative stress following praziquantel treatment of liver fluke infections. ${ }^{145}$ Curcumin administered to Opisthorchis viverrini-infected, praziquantel-treated hamsters 
significantly decreased eosinophil infiltration; increased mononuclear cell infiltration; increased transcriptional and translational expression of Nrf2, Nrf2-regulated stress pathway genes, and HO-1; increased the ferric antioxidant activity of the plasma; decreased oxidative/nitrative stress markers; and suppressed NF- $\mathrm{KB}$ activity. ${ }^{145}$ Interestingly, a study investigating the antioxidant effects of curcumin discovered that the compound potentiated doxorubicin toxicity towards normal cardiac muscle cells by stimulating doxorubicin-mediated ROS production and modulating the expression of anti- and pro-apoptotic proteins in favor of apoptosis induction. ${ }^{146}$

A human study conducted in India suggests that curcumin may exert significant preventative effects against arsenic-induced carcinogenesis. ${ }^{147}$ Asymptomatic, chronically arsenic-exposed volunteers $(n=66)$ treated with curcumin showed significant reductions in 8-hydroxy-20deoxyguanosine levels and oxoguanine glycosylase expression, both of which are upregulated by arsenic. ${ }^{147}$ Curcumin treatment also induced the transcriptional and translational expression of DNA repair enzymes involved in the base excision repair and nonhomologous end-joining pathways. ${ }^{147}$ The presence of curcumin exerted protective effects in larvae of Drosophila melanogaster against the potential industrial and household toxins benzene, toluene, and xylene. ${ }^{148}$ Specifically, curcumin reduced cytochrome P450 activity, GST levels, oxidative stress parameters, and genotoxic and apoptotic endpoints caused by exposure to these compounds. ${ }^{148} \mathrm{An}$ in vivo study investigating the protective effects of curcumin against lead-induced cardiotoxicity in rats, indicated that intraperitoneal administration of curcumin alone, or in conjunction with exercise, was able to lower lead-induced levels of high sensitivity-C reactive protein, creatine kinase-MB, malondialdehyde, and LDL, while simultaneously increasing glutathione peroxidase, TAC, and high-density lipoprotein levels. ${ }^{149}$ Curcumin pretreatment of human embryo lung fibroblast cells prevented cell cycle changes induced by the occupational toxin silica by downregulation of E2F-4 and overexpression of cyclin D1 and cyclin-dependent kinase $4 .{ }^{150} \mathrm{An}$ in vivo study revealed that curcumin could successfully suppress selenium-induced cataractogenesis in rats by inhibiting selenium-mediated upregulation of $\alpha \mathrm{A}$-crystallin, $\alpha \mathrm{B}$-crystallin, and heat shock protein 90 expression. ${ }^{151}$

\section{Conclusion}

The field of inquiry into the pharmacological properties and applications of curcumin is a rapidly growing, progressing, and expanding enterprise, as evidenced by the studies reviewed above and the many more being reported every day. The pharmacokinetic parameters of the parent drug remain a significant challenge to widespread clinical use of curcumin for the treatment of many human diseases, but a tremendous amount of promising work is being conducted to circumvent this problem through the utilization of unique delivery systems and chemical modifications. This work may also tremendously benefit the field of curcumin study by producing patentable drug constructs that could tweak the curiosity of well-funded and well-resourced pharmaceutical companies worldwide to seriously consider developing and producing curcumin as a drug. The above reviewed studies, as well as many more not described in this work, suggest that the potential clinical application of curcumin is extremely vast, owing to its diverse and potent array of pharmacological effects in almost all of the major organ systems of the human body. These effects are supported by an equally vast amount of molecular targets and mechanisms of action displayed by the compound in a large host of cell types both in vitro and in vivo. Coupled with the fact that preliminary studies suggest that the polyphenol is relatively safe for human administration, curcumin's diverse molecular targeting capability may make it a true "go-to" agent for the prevention and therapy of numerous human pathological conditions, particularly inflammatory-based processes, and, perhaps most importantly, cancer. Hippocrates is famous for once saying, "Let food be thy medicine and medicine be thy food." Curcumin may indeed be the medicine and the food that the world has long been looking for.

\section{Acknowledgments}

The authors' work cited in this review was supported in part by the NIH (CA115414 to SH) and the American Cancer Society (RSG-08-135-01-CNE to SH).

\section{Disclosure}

No conflicts of interest were declared in relation to this paper.

\section{References}

1. Litwinienko G, Ingold K. Abnormal solvent effects on hydrogen atom abstraction. 2. Resolution of the curcumin antioxidant controversy. The role of sequential proton loss electron transfer. J Org Chem. 2004;69(18): 5888-5896.

2. Aggarwal B, Kumar A, Bharti A. Anticancer potential of curcumin: preclinical and clinical studies. Anticancer Res. 2003;23(1A):363-398.

3. Sharma R, Gescher A, Steward W. Curcumin: the story so far. Eur J Cancer. 2005;41(13):1955-1968.

4. Shishodia S, Sethi G, Aggarwal B. Curcumin: getting back to the roots. Ann NY Acad Sci. 2005;1056:206-217. 
5. Aggarwal B, Shishodia S. Molecular targets of dietary agents for prevention and therapy of cancer. Biochem Pharmacol. 2006;71(10):1397-1421.

6. Mehta K, Pantazis P, McQueen T, Aggarwal B. Antiproliferative effect of curcumin (diferuloylmethane) against human breast tumor cell lines. Anticancer Drugs. 1997;8(5):470-481.

7. Hanif R, Qiao L, Shiff S, Rigas B. Curcumin, a natural plant phenolic food additive, inhibits cell proliferation and induces cell cycle changes in colon adenocarcinoma cell lines by a prostaglandin-independent pathway. J Lab Clin Med. 1997;130(6):576-584.

8. Kuo M, Huang T, Lin J. Curcumin, an antioxidant and anti-tumor promoter, induces apoptosis in human leukemia cells. Biochim Biophys Acta. 1996;1317:95-100.

9. Piwocka K, Zablocki K, Wieckowski M, et al. A novel apoptosis-like pathway, independent of mitochondria and caspases, induced by curcumin in human lymphoblastoid T (Jurkat) cells. Exp Cell Res. 1999; 249(2):299-307.

10. Han S, Chung S, Robertson D, Ranjan D, Bondada S. Curcumin causes the growth arrest and apoptosis of $\mathrm{B}$ cell lymphoma by downregulation of egr-1, c-myc, bcl-XL, NF-kappa B, and p53. Clin Immunol. 1999; 93(2):152-161.

11. Jee S, Shen S, Tseng C, Chiu H, Kuo M. Curcumin induces a p53dependent apoptosis in human basal cell carcinoma cells. $J$ Invest Dermatol. 1998;111(4):656-661.

12. Mukhopadhyay A, Bueso-Ramos C, Chatterjee D, Pantazis P, Aggarwal B. Curcumin downregulates cell survival mechanisms in human prostate cancer cell lines. Oncogene. 2001;20(52): 7597-7609.

13. Beevers C, Chen L, Liu L, et al. Curcumin disrupts the mammalian target of rapamycin-raptor complex. Cancer Res. 2009;69(3):1000-1008.

14. Beevers C, Li F, Liu L, Huang S. Curcumin inhibits the mammalian target of rapamycin-mediated signaling pathways in cancer cells. Int $J$ Cancer. 2006;119(4):757-764.

15. Bush J, Cheung K Jr, Li G. Curcumin induces apoptosis in human melanoma cells through a Fas receptor/caspase-8 pathway independent of p53. Exp Cell Res. 2001;271(2):305-314.

16. Gupta S, Kim J, Prasad S, Aggarwal B. Regulation of survival, proliferation, invasion, angiogenesis, and metastasis of tumor cells through modulation of inflammatory pathways by nutraceuticals. Cancer Metastasis Rev. 2010;29(3):405-434.

17. Jurenka J. Anti-inflammatory properties of curcumin, a major constituent of Curcuma longa: a review of preclinical and clinical research. Altern Med Rev. 2009;14(2):141-153.

18. Zhou H, Beevers C, Huang S. The targets of curcumin. Curr Drug Targets. 2011;12(3):332-347.

19. Thangapazham R, Sharma A, Maheshwari R. Multiple molecular targets in cancer chemoprevention by curcumin. AAPS J. 2006; 8(3):E443-E449.

20. Duvoix A, Blasius R, Delhalle S, et al. Chemopreventive and therapeutic effects of curcumin. Cancer Lett. 2005;223(2):181-190.

21. Aggarwal B, Shishodia S. Suppression of the nuclear factor- $\mathrm{\kappa B}$ activation pathway by spice-derived phytochemicals: reasoning for seasoning. Ann NY Acad Sci. 2004;1030:434-441.

22. Dorai T, Aggarwal B. Role of chemopreventive agents in cancer therapy. Cancer Lett. 2004;215(2):129-140.

23. Aggarwal B, Takada Y, Oommen O. From chemoprevention to chemotherapy: common targets and common goals. Expert Opin Investig Drugs. 2004;13(10):1327-1338.

24. Surh Y. Anti-tumor promoting potential of selected spice ingredients with antioxidative and anti-inflammatory activities: a short review. Food Chem Toxicol. 2002;40(8):1091-1097.

25. Bremner P, Heinrich M. Natural products as targeted modulators of the nuclear factor-KB pathway. J Pharm Pharmacol. 2002;54(4):453-473.

26. Bengmark S. Curcumin, an atoxic antioxidant and natural NF- $\mathrm{kB}$, cyclooxygenase-2, lipooxygenase, and inducible nitric oxide synthase inhibitor: a shield against acute and chronic diseases. JPEN. 2006; 30(1):45-51.
27. Wallace J. Nutritional and botanical modulation of the inflammatory cascade - eicosanoids, cyclooxygenases, and lipoxygenases - as an adjunct in cancer therapy. Integr Cancer Ther. 2002;1(1):7-37.

28. Surh Y, Chun K, Cha H, et al. Molecular mechanisms underlying chemopreventive activities of anti-inflammatory phytochemicals: downregulation of COX-2 and iNOS through suppression of NF-[kappa]B activation. Mutat Res. 2001;480-481:243-268.

29. Cuendet M, Pezzuto J. The role of cyclooxygenase and lipoxygenase in cancer chemoprevention. Drug Metabol Drug Interact. 2000; 17(1-4):109-157.

30. Lin J. Suppression of protein kinase $\mathrm{C}$ and nuclear oncogene expression as possible action mechanisms of cancer chemoprevention by curcumin. Arch Pharm Res. 2004;27:683-692.

31. Gopalakrishna R, Jaken S. Protein kinase C signaling and oxidative stress. Free Radic Biol Med. 2000;28(9):1349-1361.

32. Lin J, Chen Y, Huang Y, Lin-Shiau S. Suppression of protein kinase $\mathrm{C}$ and nuclear oncogene expression as possible molecular mechanisms of cancer chemoprevention by apigenin and curcumin. $J$ Cell Biochem Suppl. 1997;28-29:39-48.

33. Sarkar F, Li Y. Cell signaling pathways altered by natural chemopreventive agents. Mutat Res. 2004;555(1-2):53-64.

34. van Iersel M, Ploemen J, Lo Bello M, Federici G, Van Bladeren P. Interactions of alpha, beta-unsaturated aldehydes and ketones with human glutathione S-transferase P1-1. Chem Biol Interact. 1997;108(1-2):67-78.

35. Singhal S, Awasthi S, Pandya U, et al. The effect of curcumin on glutathione-linked enzymes in K562 human leukemia cells. Toxicol Lett. 1999;109(1-2):87-95.

36. Awasthi S, Pandya U, Singhal S, et al. Curcumin-glutathione interactions and the role of human glutathione S-transferase P1-1. Chem Biol Interact. 2000;128(1):19-38.

37. Hayeshi R, Mutingwende I, Mavengere W, Masiyanise V, Mukanganyama S. The inhibition of human glutathione S-transferases activity by plant polyphenolic compounds ellagic acid and curcumin. Food Chem Toxicol. 2007;45(2):286-295.

38. Zhou H, Luo Y, Huang S. Updates of mTOR inhibitors. Anticancer Agents Med Chem. 2010;10(7):571-581.

39. Lin J. Molecular targets of curcumin. Adv Exp Med Biol. 2007;595: 227-243.

40. Payton F, Sandusky P, Alworth W. NMR Study of the Solution Structure of Curcumin. J Nat Prod. 2007;70(2):143-146.

41. Zhao B, Li X, Ho R, Cheng S, Xin W. Scavenging effect of extracts of green tea and natural antioxidants on active oxygen radicals. Cell Biophys. 1989;14:175-185.

42. Choi H, Chun Y, Kim S, Kim M, Park J. Curcumin inhibits hypoxiainducible factor-1 by degrading aryl hydrocarbon receptor nuclear translocator: a mechanism of tumor growth inhibition. Mol Pharmacol. 2006;70(5):1664-1671.

43. Sharma R, Steward W, Gescher A. Pharmacokinetics and pharmacodynamics of curcumin. Adv Exp Med Biol. 2007;595:453-470.

44. Witchitnithad W, Nimmannit U, Wacharasindhu S, Rojsitthisak P. Synthesis, characterization and biological evaluation of succinate prodrugs of curcuminoids for colon cancer treatment. Molecules. 2011; 16(2):1888-1900.

45. Han Y, Zhu J, Wang Y, Wang X, Liao Y. A simple RP-HPLC method for the simultaneous determination of curcumin and its prodrug, curcumin didecanoate, in rat plasma and the application to pharmacokinetic study. Biomed Chromatogr. 2011 Feb 4. [Epub ahead of print.]

46. Gupta N, Dixit V. Bioavailability enhancement of curcumin by complexation with phosphatidyl choline. J Pharm Sci. 2011;100(5): 1987-1995.

47. Pandelidou M, Dimas K, Georgopoulos A, Hatziantoniou S, Demetzos C. Preparation and characterization of lyophilised EGG PC liposomes incorporating curcumin and evaluation of its activity against colorectal cancer cell lines. J Nanosci Nanotechnol. 2011;11(2):1259-1266.

48. Cuomo J, Appendino G, Dern A, et al. Comparative absorption of a standardized curcuminoid mixture and its lecithin formulation. $J$ Nat Prod. 2011;74(4):664-669. 
49. Shao J, Zheng D, Jiang Z, et al. Curcumin delivery by methoxy polyethylene glycol-poly(caprolactone) nanoparticles inhibits the growth of C6 glioma cells. Acta Biochim Biophys Sin. 2011;43(4): 267-274.

50. Bhawana, Basniwal R, Buttar H, Jain V, Jain N. Curcumin nanoparticles: preparation, characterization, and antimicrobial study. J Agric Food Chem. 2011;59(5):2056-2061.

51. Shahani K, Panyam J. Highly loaded, sustained-release microparticles of curcumin for chemoprevention. J Pharm Sci. 2011;100(7):2599-2609.

52. Zhang F, Koh G, Jeansonne D, et al. A novel solubility-enhanced curcumin formulation showing stability and maintenance of anticancer activity. J Pharm Sci. 2011;100(7):2778-2789.

53. Suwannateep N, Banlunara W, Wanichwecharungruang S, et al. Mucoadhesive curcumin nanospheres: biological activity, adhesion to stomach mucosa and release of curcumin into the circulation. J Control Release. 2011;151(2):176-182.

54. Bansal S, Vadhanam M, Gupta R. Development and in vitro-in vivo evaluation of polymeric implants for continuous systemic delivery of curcumin. Pharm Res. 2011;28(5):1121-1130.

55. Liu R, Liu Z, Zhang C, Zhang B. Gelucire44/14 as a novel absorption enhancer for drugs with different hydrophilicities: in vitro and in vivo improvement on transcorneal permeation. J Pharm Sci. 2011;108(16):6615-6620.

56. Liu C, Chang F. Development and characterization of eucalyptol microemulsions for topic delivery of curcumin. Chem Pharm Bull. 2011;59(2):172-178.

57. Hassaninasab A, Hashimoto Y, Tomita-Yokotani K, Kobayashi M. Discovery of the curcumin metabolic pathway involving a unique enzyme in an intestinal microorganism. Proc Natl Acad Sci U S A. 2011;108(16):6615-6620.

58. Kundu P, De R, Pal I, et al. Curcumin alleviates matrix metalloproteinase-3 and -9 activities during eradication of Helicobacter pylori infection in cultured cells and mice. PLoS ONE. 2011;6(1):e16306.

59. Neelofar K, Shreaz S, Rimple B, et al. Curcumin as a promising anticandidal of clinical interest. Can J Microbiol. 2011;57(3): 204-210.

60. Zhang H, Ruan Z, Sang W. HDAC1/NFאB pathway is involved in curcumin inhibiting of Tat-mediated long terminal repeat transactivation. J Cell Physiol. 2011 Feb 22. [Epub ahead of print.]

61. Seal A, Aykkal R, Babu R, Ghosh M. Docking study of HIV-1 reverse transcriptase with phytochemicals. Bioinformation. 2011;5(10): 430-439.

62. Zandi K, Ramedani E, Mohammadi K, et al. Evaluation of antiviral activities of curcumin derivatives against HSV-1 in Vero cell line. Nat Prod Commun. 2010;5(12):1935-1938.

63. Binion D, Heidermann J, Li M, et al. Vascular cell adhesion molecule-1 expression in human intestinal microvascular endothelial cells is regulated by PI 3-kinase/Akt/MAPK/NF-kappaB: inhibitory role of curcumin. Am J Physiol Gastrointest Liver Physiol. 2009;297(2): G259-G268.

64. Kim Y, Ahn Y, Hong M, et al. Curcumin attenuates inflammatory responses of TNF-alpha-stimulated human endothelial cells. J Cardiovasc Pharmacol. 2007;50(1):41-49.

65. Madan B, Ghosh B. Diferuloylmethane inhibits neutrophil infiltration and improves survival of mice in high-dose endotoxin shock. Shock. 2003;19(1):91-96.

66. Belcaro G, Cesarone M, Dugall M, et al. Efficacy and safety of Meriva $^{\circledR}$, a curcumin-phosphatidylcholine complex, during extended administration in osteoarthritis patients. Altern Med Rev. 2010;15(4): 337-344.

67. Zhong F, Chen H, Han L, Jin Y, Wang W. Curcumin attenuates lipopolysaccharide-induced renal inflammation. Biol Pharm Bull. 2011;34(2):226-232.

68. Guimaraes M, Coimbra L, de Aquino S, et al. Potent anti-inflammatory effects of systemically administered curcumin modulate periodontal disease in vivo. J Periodontal Res. 2011;46(2):269-279.
69. Guimaraes M, de Aquino S, Coimbra L, et al. Curcumin modulates the immune response associated with LPS-induced periodontal disease in rats. Innate Immun. 2011 Jan 17. [Epub ahead of print.]

70. Pandey M, Kumar S, Thimmulappa R, et al. Design, synthesis and evaluation of novel PEGylated curcumin analogs as potent Nrf2 activators in human bronchial epithelial cells. Eur J Pharm Sci. 2011;43 (1-2):16-24.

71. Tan X, Poulose E, Raveendran W, et al. Regulation of the expression of cyclooxygenases and production of prostaglandin $I(2)$ and $E(2)$ in human coronary artery endothelial cells by curcumin. J Physiol Pharmacol. 2011;62(1):21-28.

72. Ciftci O, Tanyildizi S, Godekmerdan A. Curcumin, myrecen and cineol modulate the percentage of lymphocyte subsets altered by 2,3,7,8Tetracholorodibenzo-p-dioxins (TCDD) in rats. Hum Exp Toxicol. 2011 Mar 30. [Epub ahead of print.]

73. Ciftici O, Ozdemir I, Tanyildizi S, Yildiz S, Oguzturk H. Antioxidative effects of curcumin, \{beta $\}$-myrcene and 1,8-cineole against 2,3,7,8tetrachlorodibenzo-p-dioxin-induced oxidative stress in rats liver. Toxicol Ind Health. 2011;27(5):447-453.

74. Forward N, Conrad D, Power Coombs M, et al. Curcumin blocks interleukin (IL)-2 signaling in T-lymphocytes by inhibiting IL-2 synthesis, CD25 expression, and IL-2 receptor signaling. Biochem Biophys Res Commun. 2011;407(4):801-806.

75. Shin D, Seo E, Pang B, et al. Inhibition of Ca2+-release-activated $\mathrm{Ca} 2+$ channel (CRAC) and $\mathrm{K}+$ channels by curcumin in Jurkat-T cells. J Pharmacol Sci. 2011;115(2):144-154.

76. Srivastava G, Mehta J. Currying the heart: curcumin and cardioprotection. J Cardiovasc Pharmacol Ther. 2009;14(1):22-27.

77. Pirvulescu M, Gan A, Stan D, et al. Curcumin and a Morus alba extract reduce pro-inflammatory effects of resistin in human endothelial cells. Phytother Res. 2011 Mar 28. [Epub ahead of print.]

78. Li M, Liu C, Bin J, et al. Mutant hypoxia inducible factor- $1 \alpha$ improves angiogenesis and tissue perfusion in ischemic rabbit skeletal muscle. Microvasc Res. 2011;81(1):26-33.

79. Nakmareong S, Kukongviriyapan U, Pakdeechote P, et al. Antioxidant and vascular protective effects of curcumin and tetrahydrocurcumin in rats with L: -NAME-induced hypertension. Naunyn Schmiedebergs Arch Pharmacol. 2011;383(5):519-529.

80. Kolodziejczyk J, Olas B, Saluk-Juszczak J, Wachowicz B. Antioxidative properties of curcumin in the protection of blood platelets against oxidative stress in vitro. Platelets. 2011;22(4): 27-276.

81. Mahfouz M, Zhou S, Kummerow F. Curcumin prevents the oxidation and lipid modification of LDL and its inhibition of prostacyclin generation by endothelial cells in culture. Prostaglandins Other Lipid Mediat. 2009;90(1-2):13-20.

82. Yu Y, Lin H. Curcumin prevents human aortic smooth muscle cells migration by inhibiting of MMP-9 expression. Nutr Metab Cardiovasc Dis. 2010;20(2):125-132.

83. Yuan H, Kuang S, Zheng X, et al. Curcumin inhibits cellular cholesterol accumulation by regulating SREBP-1/caveolin-1 signaling pathway in vascular smooth muscle cells. Acta Pharmacol Sin. 2008; 29(5):555-563.

84. Olszanecki R, Jawien J, Gajda M, et al. Effect of curcumin on atherosclerosis in apoE/LDLR-double knockout mice. J Physiol Pharmacol. 2005;56(4):627-635.

85. Kim M, Kim Y. Hypocholesterolemic effects of curcumin via upregulation of cholesterol 7a-hydroxylase in rats fed a high fat diet. Nutr Res Pract. 2010;4(3):191-195.

86. Kumar P, Malhotra P, Ma K, et al. SREBP 2 mediates the modulation of intestinal NPC1 L1 expression by curcumin. Am J Physiol Gastrointest Liver Physiol. 2011 Apr 28. [Epub ahead of print.]

87. Yadav V, Aggarwal B. Curcumin: a component of the golden spice, targets multiple angiogenic pathways. Cancer Biol Ther. 2011; 11(2):236-241.

88. Varinska L, Mirossay L, Mojzisova G, Mojzis J. Antiangogenic effect of selected phytochemicals. Pharmazie. 2010;65(1):57-63. 
89. El-Azab M, Hishe H, Moustafa Y, El-Awady e-S. Anti-angiogenic effect of resveratrol or curcumin in Ehrlich ascites carcinoma-bearing mice. Eur J Pharmacol. 2011;652(1-3):7-14.

90. Sun Z, Chen G, Zhang W, et al. Curcumin dually inhibits both mammalian target of rapamycin and nuclear factor-?B pathways through a crossed phosphatidylinositol 3-kinase/Akt/I?B kinase complex signaling axis in adenoid cystic carcinoma. Mol Pharmacol. 2011; 79(1):106-118

91. Prakobwong S, Khoontawad J, Yongvanit P, et al. Curcumin decreases cholangiocarcinogenesis in hamsters by suppressing inflammationmediated molecular events related to multistep carcinogenesis. Int $J$ Cancer. 2011;129(1):88-100.

92. Shahani K, Swaminathan S, Freeman D, et al. Injectable sustained release microparticles of curcumin: a new concept for cancer chemoprevention. Cancer Res. 2010;70(11):4443-4452.

93. Song M, Yim J, Yim J, et al. Use of curcumin to decrease nitric oxide production during the induction of antitumor responses by IL-2. J Immunother. 2011;34(2):149-164.

94. Soung Y, Chung J. Curcumin inhibition of the functional interaction between integrin $\alpha 6 \beta 4$ and the epidermal growth factor receptor. $\mathrm{Mol}$ Cancer Ther. 2011;10(5):883-891.

95. Fang H, Chen S, Guo D, Pan S, Yu Z. Proteomic identification of differentially expressed proteins in curcumin-treated MCF-7 cells. Phytomedicine. 2011 Jan 14. [Epub ahead of print.]

96. Sreekanth C, Bava S, Sreekumar E, Anto R. Molecular evidences for the chemosensitizing efficacy of liposomal curcumin in paclitaxel chemotherapy in mouse models of cervical cancer. Oncogene. 2011 Feb 14. [Epub ahead of print.]

97. Prakobwong S, Gupta S, Kim J, et al. Curcumin suppresses proliferation and induces apoptosis in human biliary cancer cells through modulation of multiple cell signaling pathways. Carcinogenesis. 2011 Feb 16. [Epub ahead of print.]

98. Lee Y, Kim N, Suh Y, Lee C. Involvement of ROS in curcumininduced autophagic cell death. Korean J Physiol Pharmacol. 2011; 15(1):1-7.

99. Kim K, Lee C. Curcumin induces downregulation of E2F4 expression and apoptotic cell death in HCT116 human colon cancer cells; involvement of reactive oxygen species. Korean J Physiol Pharmacol. 2010;14(6):391-397.

100. Carroll R, Benya R, Turgeon D, et al. Phase IIa clinical trial of curcumin for the prevention of colorectal neoplasia. Cancer Prev Res. 2011;4(3):354-356

101. He Z, Shi C, Wen H, et al. Upregulation of $\mathrm{p} 53$ expression in patients with colorectal cancer by administration of curcumin. Cancer Invest 2011;29(3):208-213.

102. Gou M, Men K, Shi H, et al. Curcumin-loaded biodegradable polymeric micelles for colon cancer therapy in vitro and in vivo. Nanoscale. 2011;3(4):1558-1567.

103. Wong T, Takeda T, Li B, et al. Curcumin disrupts uterine leiomyosarcoma cells through AKT-mTOR pathway inhibition. Gynecol Oncol. 2011;122(1):141-148.

104. Wang L, Wang L, Song R, et al. Targeting sarcoplasmic/endoplasmic reticulum $\mathrm{Ca} 2+-\mathrm{ATPase} 2$ by curcumin induces ER stress-associated apoptosis for treating human liposarcoma. Mol Cancer Ther. 2011 10(3):461-471.

105. Lim K, Bisht S, Bar E, Maitra A, Eberhart C. A polymeric nanoparticle formulation of curcumin inhibits growth, clonogenicity and stem-like fraction in malignant brain tumors. Cancer Biol Ther. 2011; 11(5):464-473

106. Aravindan N, Veeraraghavan J, Madhusoodhanan R, Herman T, Natarajan M. Curcumin regulates low-linear energy transfer $\gamma$-radiationinduced NF- $\mathrm{KB}$-dependent telomerase activity in human neuroblastoma cells. Int J Radiat Oncol Biol Phys. 2011;79(4):1206-1215.

107. Ghoneum M, Gollapudi S. Synergistic apoptotic effect of Arabinoxylan rice bran (MGN-3/Biobran) and curcumin (turmeric) on human multiple myeloma cell line U266 in vitro. Neoplasma. 2011; 58(2):118-123.
108. Ikeda R, Vermeulen L, Lau E, et al. Establishment and characterization of irinotecan-resistant human non-small cell lung cancer A549 cells. Mol Med Report. 2010;3(6):1031-1034.

109. Liao S, Xia J, Chen Z, et al. Inhibitory effect of curcumin on oral carcinoma CAL-27 cells via suppression of Notch-1 and NF- $\kappa B$ signaling pathways. J Cell Biochem. 2011;112(4):1055-1065.

110. Chen J, Tang Y, Liu H, et al. Anti-proliferative and anti-metastatic effects of curcumin on oral cancer cells. Hua Xi Kou Qiang Yi Xue Za Zhi. 2011;29(1):83-86.

111. Lopez-Jornet P, Camacho-Alonso F, Gomez-Garcia F. Effect of curcumin and irradiation in PE/CA-PJ15 oral squamous cell carcinoma. Acta Odontol Scand. 2011 Feb 7. [Epub ahead of print.]

112. Teiten M, Gaascht F, Cronauer M, et al. Anti-proliferative potential of curcumin in androgen-dependent prostate cancer cells occurs through modulation of the Wingless signaling pathway. Int J Oncol. 2011; 38(3):603-611.

113. Subramaniam D, Ramalingam S, Linehan D, et al. RNA binding protein CUGBP2/CELF2 mediates curcumin-induced mitotic catastrophe of pancreatic cancer cells. PLoS ONE. 2011;6(2):e16958.

114. Kulkarni S, Dhir A. An overview of curcumin in neurological disorders. Indian J Pharm Sci. 2010;72(2):149-154.

115. Zhang X, Yin W, Shi X, Li Y. Curcumin activates Wnt/ß-catenin signaling pathway through inhibiting the activity of GSK-3ß in APPswe transfected SY5Y cells. Eur J Pharm Sci. 2011;42(5):540-546.

116. Yanagisawa D, Taguchi H, Yamamoto A, et al. Curcuminoid binds to amyloid-ß1-42 oligomer and fibril. J Alzheimers Dis. 2011;24:33-42.

117. Sagnou M, Benaki D, Triantis C, et al. Curcumin as the OO bidentate ligand in " $2+1$ " complexes with the $[\mathrm{M}(\mathrm{CO}) 3]+(\mathrm{M}=\mathrm{Re}, 99 \mathrm{mTc})$ tricarbonyl core for radiodiagnostic applications. Inorg Chem. 2011; 50(4):1295-1303.

118. Huang Z, Zhong X, Li Z, et al. Curcumin reverses corticosteroneinduced depressive-like behavior and decrease in brain BDNF levels in rats. Neurosci Lett. 2011;493(3):145-148.

119. Agarwal N, Jain S, Agarwal N, Mediratta P, Sharma K. Modulation of pentylenetetrazole-induced kindling and oxidative stress by curcumin in mice. Phytomedicine. 2011 Jan 4. [Epub ahead of print.]

120. Liu Z, Yu Y, Li X, Ross C, Smith W. Curcumin protects against A53T alpha-synuclein-induced toxicity in a PC12 inducible cell model for Parkinsonism. Pharmacol Res. 2011;63(5):439-444.

121. Lin M, Hung K, Chiu W, et al. Curcumin enhances neuronal survival in N-methyl-d-aspartic acid toxicity by inducing RANTES expression in astrocytes via PI-3K and MAPK signaling pathways. Prog Neuropsychopharmacol Biol Psychiatry. 2011;35(4):931-938.

122. King M, McCraken D, Wade F, et al. Attenuation of hematoma size and neurological injury with curcumin following intracerebral hemorrhage in mice. J Neurosurg. 2011 Mar 18. [Epub ahead of print.]

123. Sahin Kavakli H, Koca C, Alici O. Antioxidant effects of curcumin in spinal cord injury in rats. Ulus Travma Acil Cerrahi Derg. 2011;17(1): 14-18.

124. Noorafshan A, Omidi A, Karbalay-Doust A, Aliabadi E, Dehghani F. Effects of curcumin on the dorsal root ganglion structure and functiona recovery after sciatic nerve crush in rat. Micron. 2011;42(5):449-455.

125. Aggarwal B. Targeting inflammation-induced obesity and metabolic diseases by curcumin and other nutraceuticals. Annu Rev Nutr. 2010;30:173-199.

126. Shehzad A, Ha T, Subhan F, Lee Y. New mechanisms and the antiinflammatory role of curcumin in obesity and obesity-related metabolic diseases. Eur J Nutr. 2011 Mar 27. [Epub ahead of print.]

127. El-Azab M, Attia F, El-Mowafy A. Novel role of curcumin combined with bone marrow transplantation in reversing experimental diabetes: effects on pancreatic islet regeneration, oxidative stress, and inflammatory cytokines. Eur J Pharmacol. 2011;658(1):41-48.

128. Gupta S, Kumar B, Nag T, et al. Curcumin prevents experimental diabetic retinopathy in rats through its hypoglycemic, antioxidant, and anti-inflammatory mechanisms. J Ocul Pharmacol Ther. 2011;27(2):123-130. 
129. El-Moselhy M, Taye A, Sharkawi S, El-Sisi S, Ahmed A. The antihyperglycemic effect of curcumin in high fat diet fed rats. Role of TNF-a and free fatty acids. Food Chem Toxicol. 2011;49(5):1129-1140.

130. Lin J, Chen A. Curcumin diminishes the impacts of hyperglycemia on the activation of hepatic stellate cells by suppressing membrane translocation and gene expression of glucose transporter-2. Mol Cell Endocrinol. 2011;333(2):160-171.

131. Sawatpanich T, Petpiboolthai H, Punyarachun B, Anupunpisit V. Effect of curcumin on vascular endothelial growth factor expression in diabetic mice kidney induced by streptozotocin. J Med Assoc Thai. 2010;93(Suppl 2):S1-S8.

132. Zhao J, Sun X, Ye F, Tian W. Suppression of fatty acid synthase, differentiation and lipid accumulation in adipocytes by curcumin. $\mathrm{Mol}$ Cell Biochem. 2011;351(1-2):19-28.

133. Kim C, Bordenave N, Ferruzzi M, Safavy A, Kim K. Modification of curcumin with polyethylene glycol enhances the delivery of curcumin in preadipocytes and its antiadipogenic property. J Agric Food Chem. 2011;59(3):1012-1019.

134. Awasd A, El-Sharif A. Curcumin immune-mediated and anti-apoptotic mechanisms protect against renal ischemia/reperfusion and distant organ induced injuries. Int Immunopharmacol. 2011 Feb 24. [Epub ahead of print.]

135. Leonhard W, van der Wal A, Novalic Z, et al. Curcumin inhibits cystogenesis by simultaneous interference of multiple signaling pathways: in vivo evidence from a Pkd1-deletion model. Am J Physiol Renal Physiol. 2011;300(5):F1193-1202.

136. Shing C, Adams M, Fassett R, Coombes J. Nutritional compounds influence tissue factor expression and inflammation of chronic kidney disease patients in vitro. Nutrition. 2011 Feb 3. [Epub ahead of print.]

137. Liu K, Shen L, Wang J, et al. The preventative role of curcumin on the lung inflammatory response induced by cardiopulmonary bypass in rats. J Surg Res. 2010 Dec 31. [Epub ahead of print.]

138. Yu Y, Miki H, Nakamura Y, et al. Curcumin and genistein additively potentiate G551D-CFTR. J Cyst Fibros. 2011 Mar 25. [Epub ahead of print.]

139. Kumar A, Purwar B, Shrivastava A, Pandey S. Effects of curcumin on the intestinal motility of albino rats. Indian J Physiol Pharmacol. 2010;54(3):284-288.

140. Demirovic D, Rattan S. Curcumin induces stress response and hormetically modulates wound healing ability of human skin fibroblasts undergoing ageing in vitro. Biogerontology. 2011 Mar 6. [Epub ahead of print.]
141. Naz R. Can curcumin provide an ideal contraceptive? Mol Reprod Dev. 2011;78(2):116-123.

142. Zhang Y, Cao H, Hu Y, Wang H, Zhang C. Inhibitory effect of curcumin on angiogenesis in ectopic endometrium of rats with experimental endometriosis. Int J Mol Med. 2011;27(1):87-94.

143. Bergamaschi M, Alcantara G, Queiroz R. Curcumin could prevent methemoglobinemia induced by dapsone in rats. Food Chem Toxicol. 2011;49(7):1638-1641.

144. Sookram C, Tan M, Daya R, Heffernan S, Mishra R. Curcumin prevents haloperidol-induced development of abnormal oro-facial movements: possible implications of Bcl-XL in its mechanism of action. Synapse. 2011 Jan 7. [Epub ahead of print.]

145. Charoensuk L, Pinlaor P, Prakobwong S, et al. Curcumin induces a nuclear factor-erythroid 2-related factor 2-driven response against oxidative and nitrative stress after praziquantel treatment in liver flukeinfected hamsters. Int J Parasitol. 2011 Jan 21. [Epub ahead of print.]

146. Hosseinzadeh L, Behravan J, Mosaffa F, et al. Curcumin potentiates doxorubicin-induced apoptosis in $\mathrm{H} 9 \mathrm{c} 2$ cardiac muscle cells through generation of reactive oxygen species. Food Chem Toxicol. 2011;49(5):1102-1109.

147. Roy M, Sinha D, Mukherjee S, Biswas J. Curcumin prevents DNA damage and enhances the repair potential in a chronically arsenicexposed human population in West Bengal, India. Eur J Cancer Prev. 2011;20(2):123-131.

148. Singh M, Mishra M, Sharma A, et al. Genotoxicity and apoptosis in Drosophila melanogaster exposed to benzene, toluene and xylene: attenuation by quercetin and curcumin. Toxicol Appl Pharmacol. 2011; 253(1):14-30.

149. Dabidi Roshan V, Assali M, Moghaddam A, Hosseinzadeh M, Myers J. Exercise training and antioxidants: effects on rat heart tissue exposed to lead acetate. Int J Toxicol. 2011 Mar 4. [Epub ahead of print.]

150. Jia X, Liu B, Shi X, et al. Roles of the ERK, JNK/AP-1/cyclin D1-CDK4 pathway in silica-induced cell cycle changes in human embryo lung fibroblast cells. Cell Biol Int. 2011 Feb 14. [Epub ahead of print.]

151. Manikandan R, Beulaja M, Thiagarajan R, Arumugam M. Effect of curcumin on the modulation of $\alpha \mathrm{A}$ - and $\alpha \mathrm{B}$-crystallin and heat shock protein 70 in selenium-induced cataractogenesis in Wistar rat pups. Mol Vis. 2011;17:388-394.
Botanics: Targets and Therapy

\section{Publish your work in this journal}

Botanics: Targets and Therapy is an international, peer-reviewed, open access journal focusing on the discovery and development of active compounds based upon or found naturally occurring in the plant kingdom that may have therapeutic potential in any disease state. The manuscript management system is completely online and includes a very

\section{Dovepress}

quick and fair peer-review system. Visit http://www.dovepress.com/ testimonials.php to read real quotes from published authors. 